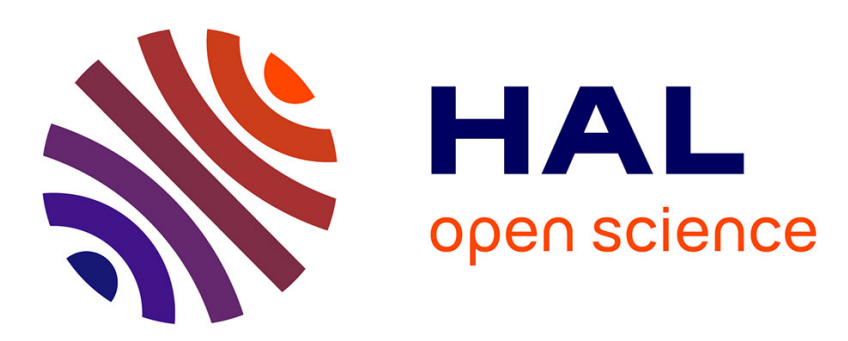

\title{
Reversible adhesion between a hydrogel and a polymer brush
}

\author{
Guillaume Sudre, Ludovic Olanier, Yvette Tran, Dominique Hourdet, \\ Costantino Creton
}

\section{- To cite this version:}

Guillaume Sudre, Ludovic Olanier, Yvette Tran, Dominique Hourdet, Costantino Creton. Reversible adhesion between a hydrogel and a polymer brush. Soft Matter, 2012, 8 (31), pp.8184. $10.1039 / \mathrm{c} 2 \mathrm{sm} 25868 \mathrm{~d}$. hal-02115824

\section{HAL Id: hal-02115824 https://hal.science/hal-02115824}

Submitted on 30 Apr 2019

HAL is a multi-disciplinary open access archive for the deposit and dissemination of scientific research documents, whether they are published or not. The documents may come from teaching and research institutions in France or abroad, or from public or private research centers.
L'archive ouverte pluridisciplinaire HAL, est destinée au dépôt et à la diffusion de documents scientifiques de niveau recherche, publiés ou non, émanant des établissements d'enseignement et de recherche français ou étrangers, des laboratoires publics ou privés. 


\section{Reversible Adhesion between a Hydrogel and a Polymer Brush}

Guillaume Sudre, Ludovic Olanier, Yvette Tran, Dominique Hourdet and Costantino Creton* Laboratory of Soft Matter Science and Engineering, ESPCI-ParisTech, 75231 Paris Cédex 05

Published in Soft Matter:

Reversible Adhesion between a Hydrogel and a Polymer Brush, Sudre G., Olanier L., Tran Y., Hourdet D., Creton C., Soft Matter, 2012, 8(31), 8184-8193.

Link to the publisher version: http://dx.doi.org/10.1039/c2sm25868d 



\section{Abstract}

We have developed a new experimental methodology to investigate the adhesive properties of hydrogels on solid surfaces under fully immersed conditions. The method, based on contact mechanics, provides time-resolved reproducible and quantitative data on the work of adhesion between a hydrogel at swelling equilibrium and a planar surface grafted with responsive brushes. We used poly( $N, N$-dimethylacrylamide) (PDMA) and polyacrylamide (PAM) as model gels and poly(acrylic acid) (PAA) as $\mathrm{pH}$ dependent polymer brush. The effect of $\mathrm{pH}$, contact time and debonding velocity on adhesive interactions was specifically investigated. As expected from molecular interactions, we found that adhesion increased as the $\mathrm{pH}$ decreased and this was attributed to the formation of hydrogen bonds at the interface. Surprisingly, however, the buildup of adhesion increased slowly with the time of contact up to one hour and depended markedly on debonding velocity despite the very elastic nature of the hydrogels. Furthermore, the maximum $\mathrm{pH}$ where adhesion was observed was significantly higher for the couple PAM/PAA than for the couple PDMA/PAA, in contrast with the onset of molecular interactions in dilute solutions. 
Although adhesion of elastic soft materials on solid surfaces in air has been the subject of decades of investigations and key results can be found in reviews, ${ }^{1-3}$ this is not the case for elastic soft materials under water. Competition between adhesive interactions and interactions with water molecules significantly complicates the problem. Furthermore such problems can be investigated with hydrophobic systems or with hydrophilic systems. A very common soft hydrophilic material which displays a kind of entropic elasticity common in rubbers is the polymer-based hydrogel. Most hydrogels are essentially networks of hydrophilic polymers which are highly swollen with water. When immersed, they swell to an equilibrium volume, controlled by a balance between entropy of mixing and conformational entropy, and behave as an incompressible solid with rubber elasticity. Yet the volume fraction of water can change as the environment changes and applied stress can also modify the chemical potential of water and change the swelling ratio. Adhesion, or more generally interactions, of such soft materials on solid surfaces is of great interest since their role as a sponge makes them suitable to deliver hydrophilic cargo to specific locations (controlled release) and provide texture in food for example.

Polymers are well-known for adsorbing onto surfaces. ${ }^{4-6}$ The reason is often that the interaction between the polymer and the surface is more favorable than that of the solvent with the surface. ${ }^{6}$ Many theoretical studies have been performed on the adsorption of polymers at surfaces to predict the conformation of the chains, the concentration of monomers at the surface which differs from that in solution, or the density of adsorbed chains at the surface. ${ }^{7-11}$

Despite the great need for quantitative underwater adhesion tests adapted to macroscopic samples, the literature remains particularly poor in this area, in particular because of a certain number of experimental complications that arise. First, in terms of interactions, usual electrostatic forces (and their derivatives) are weakened by the high dielectric constant/dissociative ability of water, requiring more sensitive measurements. Then the high solvent viscosity (relative to air) implies that the drainage of the liquid film ${ }^{12}$ can control the interaction force. The latter can be positive due to viscosity effects when the two surfaces are close even if they are not in contact. The reverse problem - of a negative force due to re-entrant liquid - occurs when pulling apart the two surfaces as the created interstitial space has to be filled. Finally, water tends to be polluted with time, from the solvation of carbon dioxide from air that modifies the acidic conditions of the water to the development of bacteria in the worst cases. 
In short, characterizing the adhesion under water or in the presence of water, on swollen materials or on adsorbed layers, involves many mechanisms, some of them specific of water which is highly polar and very dissociating, and others due to the hydrodynamic specificities of a liquid.

Historically, the experimental strategies used to probe underwater adhesion fall into two broad categories: techniques measuring forces between individual molecules or monolayers and techniques measuring forces and separation energies between macroscopic objects.

The first category, which is not the focus of the present study, includes single-molecule force spectroscopy using an atomic force microscope (AFM), ${ }^{13}$ colloidal probe spectroscopy first proposed in 1991 by Ducker et al. ${ }^{14-16}$ and surface force apparatus which has been proposed by Israelachvili and Adams in $1976{ }^{17,18}$ and which probes forces between hard surfaces decorated with ultrathin (molecular) adsorbed or grafted layers. These techniques are highly sensitive to small forces and are well adapted to the liquid environment. Results obtained however are difficult to directly extrapolate to macroscopic objects.

The second category of tests probes adhesion between macroscopic objects. Many techniques in that category are inspired by the classic analysis of Johnson, Kendall and Roberts of the adhesive sphere on a flat contact called the JKR test. In their original publication, Johnson et al. reported experiments that were conducted under water ${ }^{19}$. Twenty years later, Chaudhury and Whitesides ${ }^{20}$ carried out experiments in mixtures of water and methanol and between two identical surfaces. Other examples of the use of the JKR test under water have been reported ${ }^{21-23}$ making it a method of choice for measuring adhesion under water between hydrophobic materials.

We can however only cite two examples of using a JKR-inspired technique to measure the adhesion between hydrogels. Sakasegawa and Suzuki ${ }^{24}$ used a crossed cylinders contact geometry to measure the adhesion between hydrogels. However, their measurements were performed in air and they had to use an ink, placed on one of the cylinders, to measure the contact area on the other cylinder after the experiment. La Spina et al. ${ }^{25}$ have carried out underwater measurements: a half-spherical lens made of hydrogel was put into contact with a planar brush. However, under these conditions, measuring the contact area between the gel and the substrate cannot be carried out through the gel because of the very close refractive index of the gel and water, but the contact area was extrapolated from a side-view of the system. Inspired from the sphere-flat contact test from JKR-type experiments, an adhesive test based on the contact between a rigid substrate and a membrane was first proposed by Flory et al. ${ }^{26}$ The first method, which involves a flat hard substrate, gives access to weak energies of adhesion between soft materials by a highly sensitive inflation of the membrane. The system was adapted for underwater systems by using hydrophobic membranes. ${ }^{27}$ This technique 
has recently been used by Guvendiren et $a l^{27}$ to investigate the adhesion of membranes functionalized with block copolymers containing a block with DOPA (3,4-dihydroxy-L-phenylalanine which is a mussel adhesive protein ${ }^{28}$ ) on $\mathrm{TiO}_{2}$ substrates or tissues, such as hairless pig skin. They showed that adhesiveness was increased for both substrates by adding the DOPA-functionalization to the membranes. However, with this technique, they used the negative release pressure as an indication of adhesiveness but did not get any quantitative values for the energies of adhesion.

Here, we investigate the reversible adhesion of model hydrogels swollen to equilibrium on surfaces. To make the adhesion reversible and well controlled, the choice of functionalized surfaces was made. With these systems, it is possible to vary the interaction potential between the surface and the polymer network so that both the interaction and the macroscopic adhesion are reversible. Using neutral hydrogels for their dimensional stability, the objective is to create a reversible molecular interaction between the gel and the surface, which could lead to a macroscopic adhesion tunable by changing the environmental conditions. To reach this, we have chosen to work with short-range reversible interactions, i.e. hydrogen bonds between the hydrogel and a $\mathrm{pH}$-sensitive brush of poly(acrylic acid). With such a system, we aim at gaining insight on many parameters of the surface interactions such as the kinetics of formation of the interactions, or how they can be linked to the strength of the complexes and to the macroscopic adhesion being measured. Although molecular interactions in solution have been well studied and typically lead to the establishment of phase diagrams, the behavior of the same interactions at solid-liquid interfaces can be different due to the restrictions in translational entropy of the molecule at the interface. In particular, in water the organization of weak polyelectrolyte grafted layers is complex and depends on $\mathrm{pH}$ in ways that can be different from what is expected in the bulk. ${ }^{29}$ Answering a few of the limitations encountered in the other tests, a new experimental setup for performing underwater adhesion tests was designed. It consists of a flat-flat contact test that gives a quantitative macroscopic value of the energy of adhesion in a simple and reproducible way and that is adaptable to many different systems, synthetic or not.

\section{EXPERIMENTAL}

We have developed a new experimental setup based on the flat-flat contact test and specifically adapted it to the characterization of the adhesion of soft materials under water. The working principle is represented on Figure 1: a layer of the soft or swollen sample is attached on the bottom substrate and immersed in water; the modified hard substrate is attached on a mobile punch, which is moved down to come in contact with the soft material. If properly aligned, the two materials come 
in contact, with a contact area equal to the area of the hard material. After the preset experimental conditions have been achieved (e.g. contact stress and contact time), the probe can be pulled off at a constant velocity. During the experiment, the displacement of the punch and the force applied on it are measured as a function of time.

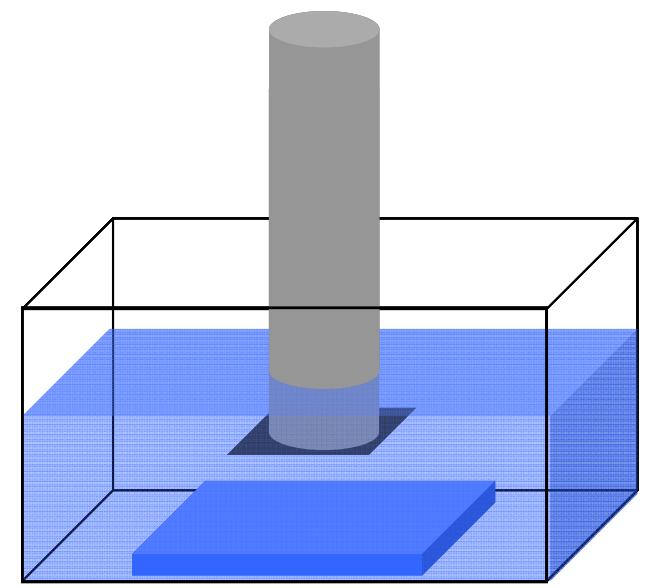

Figure 1 - Schematic representation of the immersed flat-flat contact test: the soft material is stuck at the bottom of a trough and immersed. The punch is immersed before probing the soft material.

Although the general principle is the same as that of a regular probe test, some important modifications have been made to address the needs of working underwater with hydrogels: the setup must be able to work both in air (for alignment purposes) and immersed, and the temperature and $\mathrm{pH}$ of the water need to be easily adjustable. Then the thickness of the gel layer should not be too small to avoid having a very confined gel layer and major alignment problems. This also ensures a full contact between the probe and the gel, removing, therefore, the need of a direct optical measurement of the contact area. Finally, the load cell should be sensitive enough to measure very small forces reproducibly.

A commercial Instron machine (model 5565 for tensile and compression tests) fitted with a load cell of $10 \mathrm{~N}$ was used for all the adhesion tests. The noise of the load cell is of the order of $0.1 \mathrm{mN}$ and its nominal resolution is of $0.5 \%$, from $1 \%$ to $100 \%$ of the full scale. The sample-holder of the soft and immersed gel sample has a rather complex design. It is mostly made in anodized aluminium alloys and is illustrated on Figure 2. It consists of a simple sample-holder adapted for glass slides of width $2.5 \mathrm{~cm}$ or glass discs of diameter $3 \mathrm{~cm}$ inserted in a trough (the sample trough) which has a lateral window and a bottom circular window. The trough can be thermostated by a liquid circulating 
around it in a jacket (the thermostating jacket) as can be seen in Figure 2-d. The sample trough and its jacket are clamped together with screws and a Teflon gasket sandwiched between two crosslinked polydimethylsiloxane PDMS gaskets. The whole device is then fixed to the Instron machine through an alignment device and a fixation composed of a split pin and a locknut. The alignment is insured thanks to micrometric screws placed in three points.

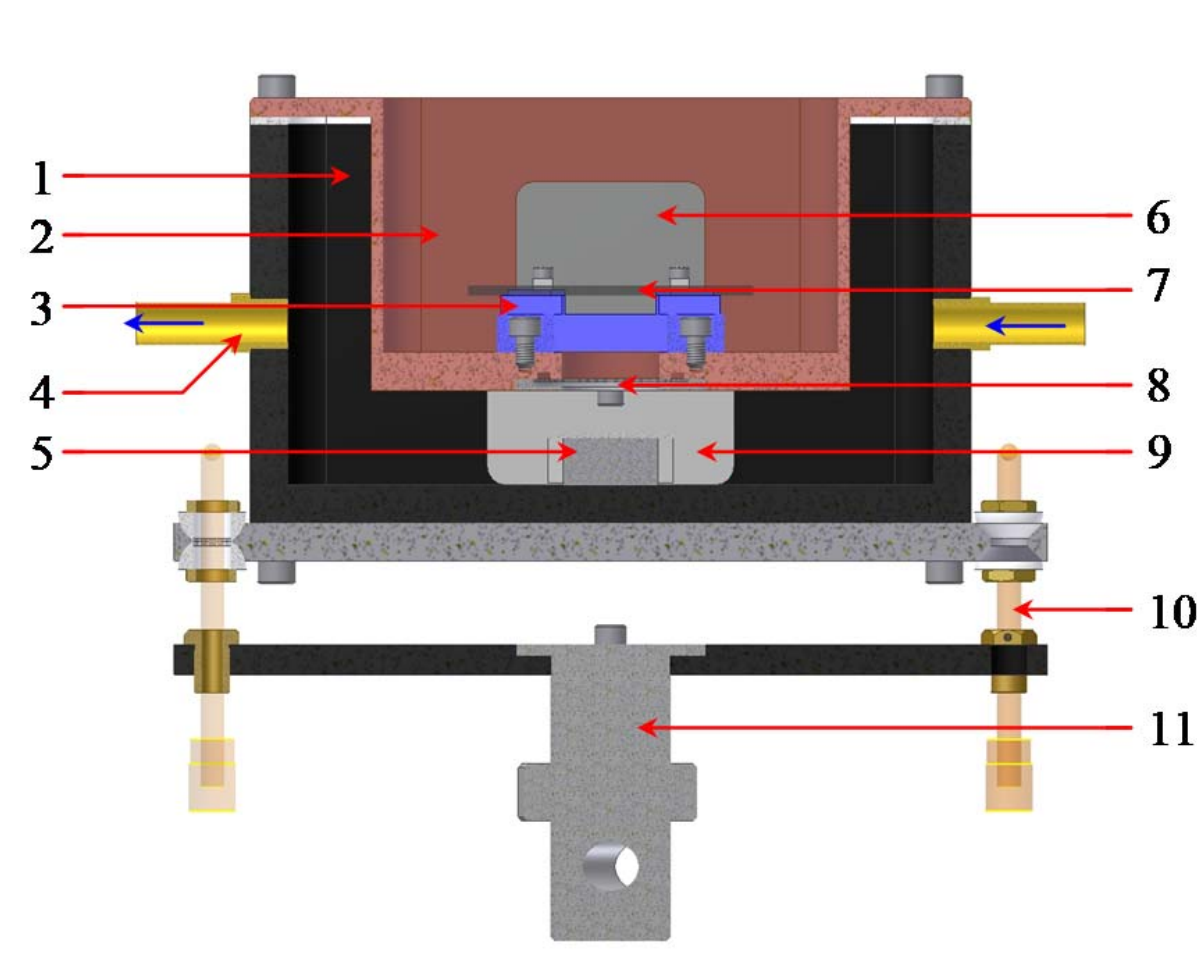

1- Heating jacket

2- Sample trough

3- Sample holder

4- Entrance of thermostated liquid

5- Mirror holder

6- Front window 2

7- Sample

8- Bottom window

9- Front window 1

1 10- Alignment device

11- Connecting device for the Instron machine

Figure 2 - A longitudinal cut back-view of the experimental setup for the measurement of adhesion on a soft swollen immersed substrate.

Visualization is made from the side - since both the trough and the jacket have aligned polycarbonate windows giving a visual on the sample - and from the bottom thanks to the lateral window of the thermostating jacket, the bottom window of the sample trough and a mirror at $45^{\circ}$. The sealing of the windows is provided from flat PDMS gaskets.

The hard surface, which consists of a silicon wafer, was stuck (with cyanoacrylate glue) on a stainless steel cylindrical punch of an appropriate diameter and the punch was fixed to the load cell with a mandrel. 
The temperature and the $\mathrm{pH}$ can be measured in situ without disturbing the measurement. The sample trough has been completely coated with a poly(vinylidene fluoride) (PVDF)-derived polymer layer; the inside screws are in stainless steel and free mechanical pieces to maintain the samples are in poly(methyl methacrylate) (PMMA). The temperature inside the sample chamber can be varied from 23 to $45^{\circ} \mathrm{C}$ in a few minutes. The change in ionic strength and $\mathrm{pH}$ can then be performed in situ.

\section{TESTED MATERIALS}

The first prerequisite to perform a flat-flat adhesion test on a soft material is to have a flat layer of this soft material firmly stuck on a hard substrate. As this material is immersed in a changing environment, it is necessary to control the swelling behavior of the material in order not to strongly modify the gel dimensions when changing the experimental conditions. Therefore, we chose carefully the chemically cross-linked hydrogel samples used in the adhesion tests. A preliminary study was carried out to make sure that the swelling at the preparation conditions remained very close to the swelling at equilibrium in pure water. The choice of a neutral hydrogel guaranteed the relatively low sensitivity of the material when changing the ionic strength or the $\mathrm{pH}$ of the water. As a hard surface, a planar silicon wafer, stuck on a stainless steel punch and functionalized with a polymer brush was used. We have chosen to work with square punches with a rather low level of confinement: the gel sample was synthesized with a thickness of about $1 \mathrm{~mm}$ and the punch size was $1 \times 1 \mathrm{~cm}^{2}$.

\section{PREPARATION OF THE GEL MOLD}

The objective is to obtain a flat gel layer with a low amplitude roughness, covalently attached to a rigid surface so that the strain and the response of the substrate to a stress of a few Newtons can be considered negligible compared to those of the gel. Two transparent substrates have been differently modified. One was tailored to covalently bind the gel, the other one to be easily removed from the gel surface after polymerization and cross-linking. Silicon can be modified thanks to its native silica layer, with small molecules able to change its surface chemistry. In order to obtain transparent surfaces, we have decided to work on silica, with various degrees of purity, from simple glass to quartz.

To chemically bond the gel to the plate, we used a surface treatment of the silica with a silane terminated with a double bond able to co-polymerize with the other monomers during the gel 
formation. The polymerization reaction results in a gel covalently bonded to the substrate. Assuming that the gel is synthesized close to its swelling equilibrium, it will not be affected by a subsequent immersion in an excess of pure water. On the other hand, the second plate was modified with a hydrophobic silane in order to easily remove the plate from the gel surface.

Prior to any surface modification, the substrate was cleaned and rejuvenated by immersion in an active "piranha" solution (70 vol\% of sulfuric acid (97\%) and 30 vol\% of hydrogen peroxide (35\%) heated at $150{ }^{\circ} \mathrm{C}$ for $20 \mathrm{~min}$ ), thoroughly rinsed with Milli-Q water and dried with a nitrogen flow. A mono-functional chlorosilane, 3-methacryloxypropyldimethylchlorosilane (92\%) was grafted on quartz plates $\left(2.5 \times 5 \mathrm{~cm}^{2}\right.$ from Ediver, France). We obtained reproducible grafted thicknesses of $8 \AA$ when it was reacted at 0.15 vol\% in extra-dry toluene during 2 hours. The hydrophobic plates were obtained from the grafting of hexamethyldisilazane (HMDZ, 98\%). The surface modification was carried out with a vapor phase method: after rejuvenation, glass substrates were placed in a closed environment with a few droplets of HMDZ for 2 hours; the glass plates were then removed from the reactor and rinsed with water. The high contact angle on the glass observed during rinsing and the absence of remaining pinned droplets on the surface without any drying were the evidence of a successful modification. To form the mold, the two glass plates were separated by a $1 \mathrm{~mm}$ thick, home-made, leakproof PDMS joint and held together using a simple binder clip.

\section{GEL SYNTHESIS}

The synthesis of poly( $N, N$-dimethylacrylamide) (PDMA) and polyacrylamide (PAM) hydrogel layers has been carried out by free radical polymerization using $N, N^{\prime}$-methylene-bis-acrylamide (MBA, Sigma-Aldrich, 99\%) as cross-linker. After dissolution of the monomer (either $\mathrm{N}, \mathrm{N}$ dimethylacrylamide, DMA, Aldrich, $99 \%$ or acrylamide, AM, Aldrich, 99\%), MBA and potassium persulfate (KPS, Sigma-Aldrich, $>99 \%$ ) in Milli-Q water, the solution was deoxygenated with a bubbling of nitrogen during $30 \mathrm{~min}$.

For PDMA hydrogels, the polymerization was initiated by a rapid addition of $N, N, N^{\prime}, N^{\prime}-$ tetramethylethylenediamine (TEMED, Sigma-Aldrich, 99\%) under stirring. The solution was then transferred to the mold placed under a nitrogen atmosphere. The red-ox initiation rapidly took place $^{30}$ and the polymerization was left to proceed during $4 \mathrm{~h}$. For PAM hydrogels, the polymerization solution was first transferred in the mold and the polymerization was initiated by heating the solution at $40{ }^{\circ} \mathrm{C}$ overnight. 
Then, the mold was opened and the $1 \mathrm{~mm}$ thick gel, stuck on the quartz plate, was immersed in MilliQ water for dialysis. Water was changed twice a day for one week and the hydrogel was finally stored in its swollen state until final use. The analysis of extractable compounds was not systematic, but no residual monomer was detected by size-exclusion chromatography (SEC) after extraction and the sol fraction was not measurable or below $2 \mathrm{wt} \%$ of the total network. This result is consistent with the work of Gundogan et al. ${ }^{31}$

We chose to work with normalized gels. The mass ratio of monomer in water was $10 \mathrm{wt} \%$ while the molar ratio of cross-linker (MBA) to monomer was set at 2 mol\%. The quantity of initiator (KPS and eventually TEMED) was set to 1 mol\% of the monomer quantity.

\section{BRUSH SYNTHESIS}

The synthesis of the PAA brushes used in this paper is described in more detail elsewhere. ${ }^{32}$ In short, after being cleaned and rejuvenated, the silicon wafers ( $380 \mu \mathrm{m}$ thick, ACM) were extensively rinsed with Milli-Q water and dried under a nitrogen flux. They were immediately placed in a reactor under nitrogen atmosphere and immersed in a 2 vol\% solution of 3-glycidoxypropyltrimethoxysilane (Aldrich, $98 \%$ ) in extra-dry toluene (Aldrich) for 5 hours at room temperature. The silicon substrate was then rinsed with toluene and dried under a nitrogen flux.

A 1 wt\% solution of carboxy-terminated poly(tert-butyl acrylate) (PtBuA) long chains $\left(M_{n}=42000\right.$ $\mathrm{g} \mathrm{mol}^{-1}, M_{\mathrm{w}}=47000 \mathrm{~g} \mathrm{~mol}^{-1}$, from Polymer Source) in tetrahydrofuran (THF, from SDS) was deposited on the epoxy-modified silicon crystal and a polymeric film was formed by solvent evaporation. The substrate topped with the PtBuA reservoir was heated at $120^{\circ} \mathrm{C}$ under vacuum during 24 hours. The substrate was thoroughly rinsed in THF. In the case of lower grafting densities, a second $1 \mathrm{wt} \%$ solution of PtBuA short chains $\left(M_{\mathrm{n}}=4200 \mathrm{~g} \mathrm{~mol}^{-1}, M_{\mathrm{w}}=4700 \mathrm{~g} \mathrm{~mol}^{-1}\right.$, from Polymer Source) in THF was then deposited on the substrate to form another reservoir of polymer. After being heated for 48 hours at $120{ }^{\circ} \mathrm{C}$ under vacuum, the silicon crystal was rinsed again, dried, and the sample was pyrolyzed at $200^{\circ} \mathrm{C}$ under vacuum for 2 hours. Finally, it was immersed overnight in Milli-Q water equilibrated at $\mathrm{pH}$ 2. The characteristics of PAA brushes are given in Table 1. 
Table 1 - Characteristics of the poly(acrylic acid) brushes: molar mass $M_{\mathrm{n}}$ of the grafted chains, dry thickness $\gamma$ and grafting density $\sigma$ for the samples used in this study. The total grafting density $\sigma^{\text {tot }}$, the mean distance between grafting points $D$ and the total thickness $\gamma^{\text {tot }}$ are also listed.

\begin{tabular}{|lcccccc|}
\hline Brush name & $M_{\mathrm{n}}\left(\mathrm{g} \mathrm{mol}^{-1}\right)$ & $\gamma(\AA)$ & $\sigma\left(\mathrm{nm}^{-2}\right)$ & $\sigma^{\text {tot }}\left(\mathrm{nm}^{-2}\right)$ & $D(\AA)$ & $\gamma^{\text {tot }}(\AA)$ \\
\hline PAA-a & 23610 & 44 & 0.133 & 0.133 & 27 & 44 \\
\hline PAA-b & 23610 & 28 & 0.083 & 0.083 & 34 & 28 \\
\hline PAA-c & 2360 & 6 & 0.155 & & 23 & 24 \\
& 23610 & 18 & 0.053 & & & \\
\hline
\end{tabular}

\section{DRY AND WET MEASUREMENTS}

Due to the very close refractive indexes of the gel and of water, no observation of the contact area could be made under immersed conditions from below through the mirror at $45^{\circ}$.

The alignment step was therefore performed in the "in-air" state prior to any underwater measurement. The punch was approached to the gel surface and the contact was observed for contact stresses lower than that used for the adhesion test. If the contact was not complete, the gel sample was aligned until the contact was complete for a stress lower than $20 \%$ of the contact stress applied during the adhesion test. The soft sample and the hard surface were kept a little tilted to avoid the imprisonment of an air bubble during the approach leading to debonding by internal crack propagation. ${ }^{33}$ The force vs. time data of a contact experiment in air and under water are plotted in Figure 3, where the displacement has been shifted so that its minimum value is equal to zero. Three main differences can be observed between in-air and underwater measurement for experimental conditions otherwise identical (indicated by arrows). 


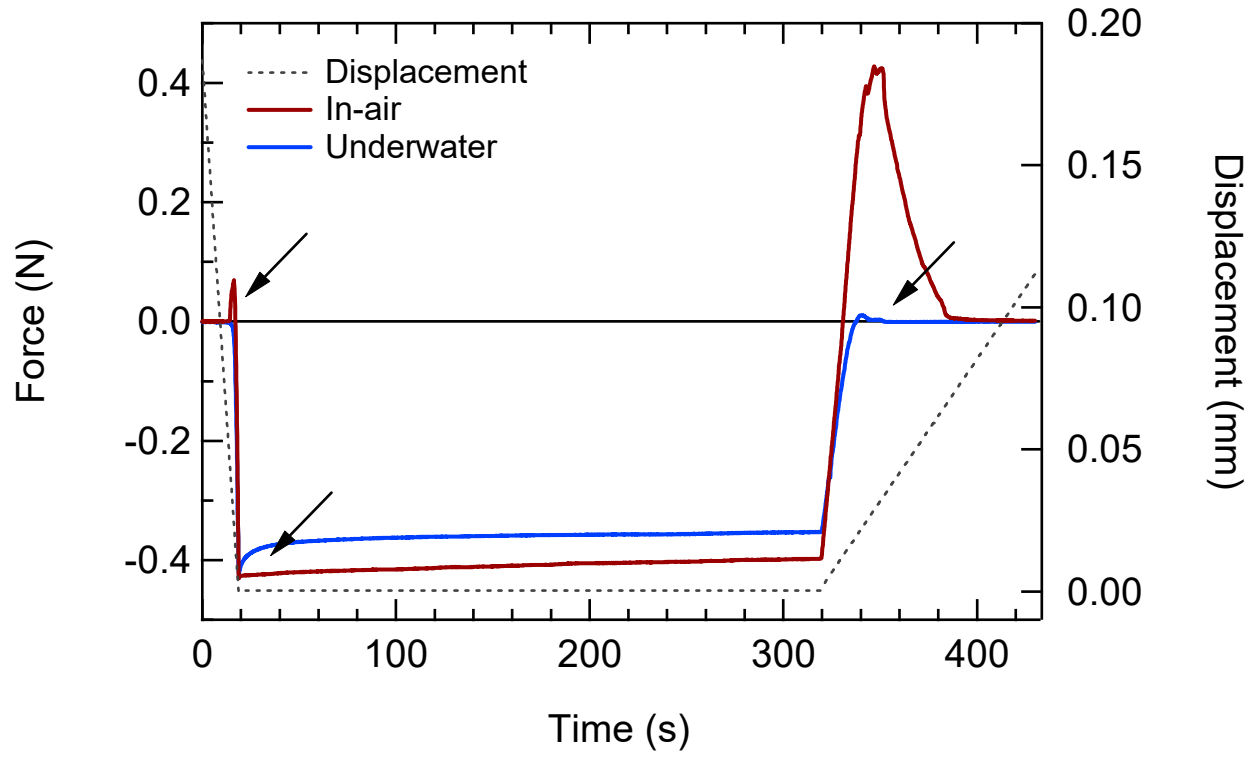

Figure 3 - Raw data obtained from an adhesion test. The force applied on the punch and its displacement are recorded as a function of time. Two results obtained between a PAA planar brush and a PDMA gel when the experiment is performed inair or underwater are represented.

In air, the gel "jumps to contact". This is a classic result for indentation of soft materials that is due to surface tension. When the punch touches the gel in one point, the triple line moves quickly so that the contact spreads rapidly and the water in the gel minimizes its contact area with air. The result is a deformation of the gel which leads to tensile forces. When immersed underwater, this effect due to the surface tension of water is eliminated since the differences in surface tension are strongly reduced.

The second difference is the relaxation of the gel under compression. In air, the relaxation is lower than $8 \%$ of the initial contact force after 300 seconds and it is two times higher in the case of an underwater measurement (about 15\%). Because the gels are very elastic, such a relaxation cannot be attributed to viscoelasticity. It is more likely to be due to syneresis. ${ }^{34,35}$

Finally, the third difference is the size of the adhesion peak, which is much higher in the case of the in-air measurement. This third difference is also due to the differences in thermodynamic work of adhesion:

$$
W_{\text {adh }}=\gamma_{\text {spe }}+\gamma_{\text {brush-IM }}+\gamma_{\text {gel-IM }}-\gamma_{\text {brush-gel }}
$$


where "IM" stands for "immersing medium" and can either be water or air, and $\gamma_{\text {spe }}$ represents an equivalent surface tension for the specific surface interactions between the gel and the brush. The surface tension between water and the gel is low since the gel is made of a hydrophilic polymer swollen with about $90 \%$ water and does not present a dry top layer. ${ }^{36,37}$ The surface tension between the PAA brush and water is rather low since PAA is hydrophilic. ${ }^{38}$ Hence, when making an underwater experiment, one removes almost all the effects of surface tensions and measures the effects of the specific interactions between the gel and the brush since $\gamma_{\text {brush-water }} \approx \gamma_{\text {gel-water }} \approx \gamma_{\text {brush-gel }} \approx 0$. In contrast, in-air measurements are at the origin of non-specific results since $\gamma_{\text {brush-air }}+\gamma_{\text {gel-air }} \approx 120$ $\mathrm{mJ} \mathrm{m} \mathrm{m}^{-2}$ are added. This difference of approximately $120 \mathrm{~mJ} \mathrm{~m}^{-2}$ is consistent with the two curves of Figure 3 where it is clearly visible that the specific interactions can be much lower than the effects due to surface tension.

\section{DATA PROCESSING}

Following the convention used for soft adhesives, the energy of adhesion is obtained from the raw data. The normalized stress is obtained by dividing the force by the punch area $A$ :

$$
\sigma=\frac{F}{A}
$$

The zero of the displacement is defined when the force becomes positive during the detachment. The strain $\varepsilon$ is then obtained by normalizing the displacement by the initial thickness of the gel layer $l_{0}$ (which is around $1 \mathrm{~mm}$ in general). After having made these definitions, it is possible to write the energy of adhesion as follows:

$$
W_{\mathrm{adh}}=l_{0} \int_{0}^{+\infty} \sigma d \varepsilon
$$




\section{CONTACT TIME}

A minimum of 10 seconds is recommended since it is the time necessary for the main part of the total mechanical relaxation of the gel to have occurred when it is underwater, as can be seen in Figure 3. We found that a minimum of $30 \mathrm{~s}$ was necessary to obtain a clear adhesion peak. Contact time effects were specifically investigated, but for comparisons between systems, we have usually worked with a contact time of $300 \mathrm{~s}$.

\section{CONTACT STRESS}

The contact stress between the brush on the punch and the gel has to be adapted to obtain a complete contact area and yet to avoid damaging the gel. For layers of gels $1 \mathrm{~mm}$ thick and with a storage modulus equal to $25 \mathrm{kPa}$, we have chosen to work at $4 \mathrm{kPa}$. At higher compressions $(10 \mathrm{kPa})$, a strong decrease of the energy of adhesion was observed. This effect can be explained by the existence of shear stresses due to incompressibility that cause a relative shearing motion at the gelbrush interface and destroy the interactions during decompression. At lower compressive stresses, a total contact between the punch and the gel requires a very good alignment.

\section{DEBONDING VELOCITY}

Mechanical tests performed on the gels (rheology and compression tests) have shown that the gels used for the adhesion tests are highly elastic. However, crack propagation can be dissipative due to local viscoelasticity at the crack tip. Even for these underwater adhesion tests, the measured adhesion is markedly dependent on the pulloff rate of the probe and these results will be discussed later. We have applied probe debonding velocities ranging from 0.1 to $100 \mu \mathrm{m} \mathrm{s}^{-1}$ and rate dependent effects are specifically discussed. However, changes in material or environment were all tested at $v=10 \mu \mathrm{m} \mathrm{s}^{-1}$.

In summary, experimental conditions are very important for this type of delicate experiments to obtain meaningful data. It is absolutely mandatory to:

- Perform a pre-alignment of the sample which insures a total contact rapidly after the first contact but which is not perfect to avoid the pinning of bubbles between the punch and the gel, and to reduce potential hydrodynamic effects and bulk dissipation in the gel.

- Impose a contact force adapted to the size of the punch and to the storage modulus of the gel to avoid damage of the gel. 
- Maintain a contact time long enough for the gel to partially relax and for the interactions to form at the interface.

- Examine effects of the debonding velocity.

\section{SETTING THE ENVIRONMENTAL CONDITIONS}

The $\mathrm{pH}$ of the gel and of the immersing solutions were equilibrated for a long time prior to use. Milli$\mathrm{Q}$ water was equilibrated at various $\mathrm{pH}$ using either hydrochloric acid or sodium hydroxide solutions ( $1 \mathrm{M}$ or $10^{-1} \mathrm{M}$ depending on the $\mathrm{pH}$ ).

\section{RESULTS}

\section{EFFECTS OF ENVIRONMENTAL CHANGES ON THE ADHESION}

One of the main goals of the study was to investigate the effect of a change in $\mathrm{pH}$ of the water on the adhesive interactions between the gel and the brush grafted on the silicon wafer.

Unless otherwise specified, these experiments were carried out with a time of contact of $300 \mathrm{~s}$, an average contact compressive stress of $4 \mathrm{kPa}$ and a debonding velocity equal to $10 \mu \mathrm{m} \mathrm{s}^{-1}$ for all the adhesion tests of this paper. Furthermore, it is important to note that all experiments reported here are perfectly reproducible for a given gel-brush pair. Hence no damage is done to the layers and the adhesion measured is perfectly reversible. Due to the difficulty in perfectly reproducing the alignment, small changes are observed when a new gel sample is used. All curves shown here are representative curves. All tests presented have been reproduced at least 3 times.

The $\mathrm{pH}$-sensitive behavior of the adhesion of a PAA brush against a PDMA gel is demonstrated in Figure 4. In this case, PDMA hydrogels equilibrated at various $\mathrm{pH}$ are probed under immersed conditions against the PAA-a brush. The adhesion peak clearly depends on the $\mathrm{pH}$ of the solution in which the gel and the brush are equilibrated. At lower $\mathrm{pH}$, when the brush is more protonated, the energy of adhesion is higher. As the $\mathrm{pH}$ increases, the adhesion is strongly reduced and at $\mathrm{pH} 4$ it is almost non-existent compared to what is observed at $\mathrm{pH}$ 2. This figure demonstrates the existence of a pH-sensitive and tunable adhesion.

The same experiment (identical duration and stress of contact) was carried out on PAM hydrogels with a PAA-b brush immersed and equilibrated at various $\mathrm{pH}$, as shown in Figure 5. Qualitatively 
similar results to those obtained with PDMA hydrogels are observed, except that adhesion is now not measurable for $\mathrm{pH}>5$. In this case also, the adhesion is strongly dependent on $\mathrm{pH}$.

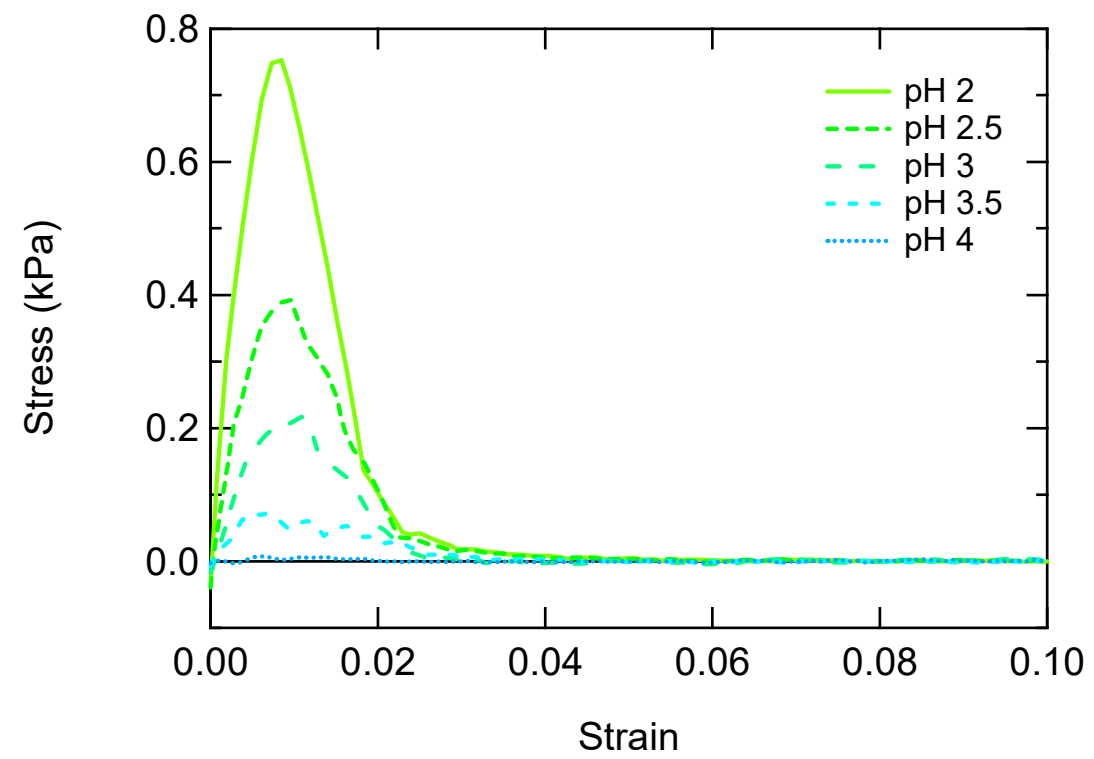

Figure 4 - Stress-strain curves in the case of adhesive forces for PDMA hydrogels equilibrated at various $\mathrm{pH}$ facing a PAA-a brush.

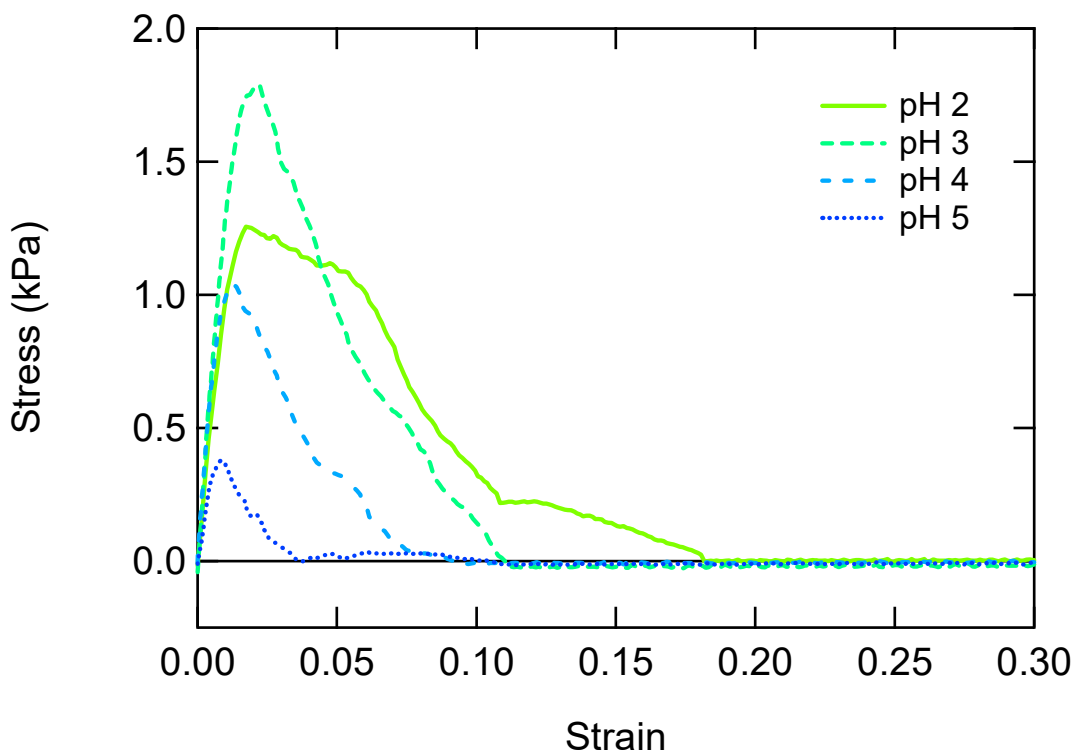

Figure 5 - Stress strain curves in the case of adhesive forces for PAM hydrogels equilibrated at various pH facing a PAA-b brush. 
The energies of adhesion of the two systems have been calculated with the methodology described in the "Data Processing" section, and plotted together as a function of $\mathrm{pH}$ in Figure 6. The adhesion on PAM hydrogels is one order of magnitude higher than on PDMA hydrogels, and the transition between adhesive interactions and the absence of interaction occurs at a higher $\mathrm{pH}$.

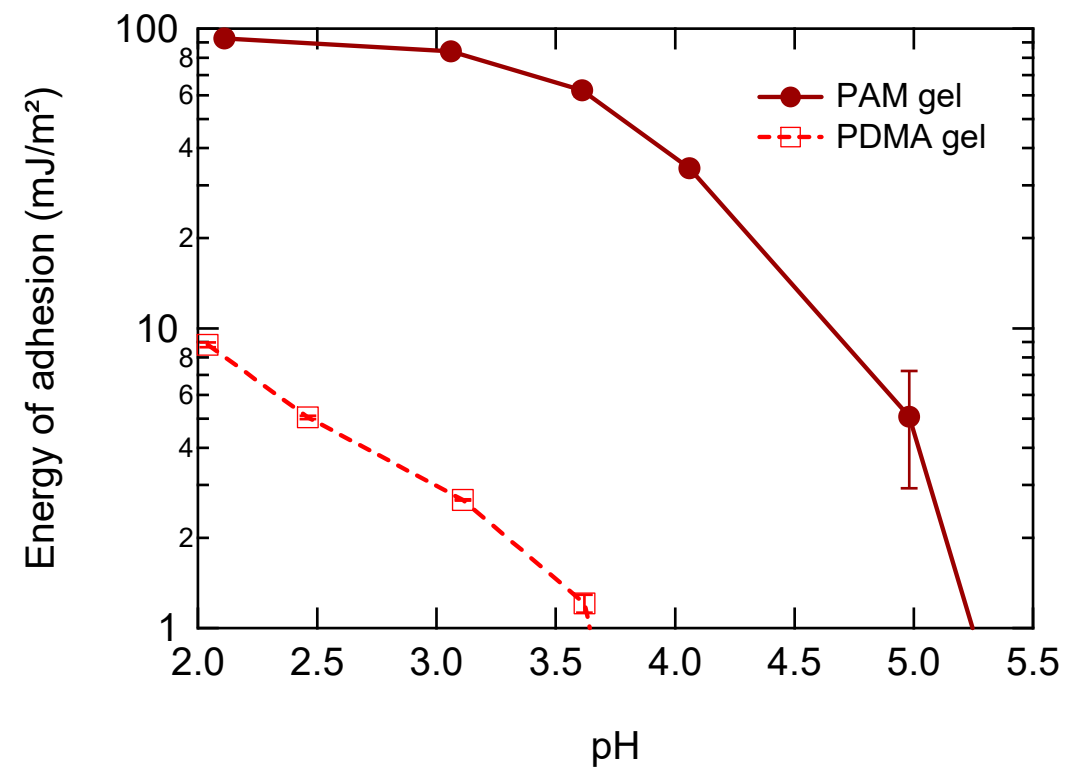

Figure 6 - Energy of adhesion between a PAA-a brush and a PDMA hydrogel or a PAA-b brush and a PAM hydrogel as a function of $\mathrm{pH}$.

Complexation experiments in dilute solution show that PAA and PDMA only form complexes at room temperature for $\mathrm{pH}<3.5$ and PAA and PMA for $\mathrm{pH}<3.2 .^{39}$ For $\mathrm{pH}$ below 3.5 , the PDMA and PAA are complexed in solution and the same complexation appears to occur at the interface between the PAA brush and the PDMA gel resulting in a macroscopic adhesion. In contrast, the onset of adhesion for the PAA brush against the PAM hydrogel is shifted to higher $\mathrm{pH}$ compared to the transition observed for the complexation of the same polymeric pair. This means that the complexation at the interface is favored in comparison with the solution.

Our original objective was to change the adhesive properties between the brush and the gel when they are in contact by changing the $\mathrm{pH}$ in situ. As a consequence, we performed adhesion tests on a PDMA hydrogel equilibrated at $\mathrm{pH} 2$ in the following way. First a standard conditions adhesion test was carried out at $\mathrm{pH}$ 2. The $\mathrm{pH}$ of the solution was then adjusted to a higher value with sodium hydroxide solutions ( $1 \mathrm{M}$ or $10^{-1} \mathrm{M}$ depending on the $\mathrm{pH}$ ) and when no variation of $\mathrm{pH}$ could be 
observed for $1 \mathrm{~min}$ in the immersing solution, another test was performed and so on. The PAA brush was a PAA-c and the results are shown in Figure 7 (top). The energies of adhesion obtained are compared with those obtained from the PDMA hydrogels previously equilibrated at a given $\mathrm{pH}$ and shown in figure 7 (bottom). Since the brush is slightly different, the energies of adhesion have been normalized by the maximum values, obtained at $\mathrm{pH} 2$. Surprisingly, even for an immersing solution at pH 9, we still obtain adhesion. This implies that the gel is not completely equilibrated due to a slower diffusion inside the gel than in the solution. It means that if the $\mathrm{pH}$ of the solution is equal to 9 , at the surface of the gel, the $\mathrm{pH}$ is probably closer to 4 inside the gel. This also implies that changing the acidity of the solution while the gel and the brush are in contact would lead to no change in adhesion if the time of contact is not long enough for the acidity to diffuse at the interface from the surrounding solution.

La Spina et $a{ }^{25}$ have performed similar experiments with PAA brushes against a hydrogel of poly[2(dimethyl amino)ethyl methacrylate] (a polybase). They found that a free standing gel detaches spontaneously from the substrate when the $\mathrm{pH}$ of the water decreases from 5.8 to 1.1. The time needed for the gel to detach is however a minimum of $7 \mathrm{~h}$. These results are consistent with ours, demonstrating that the diffusion of the acidity in the gel is slow.

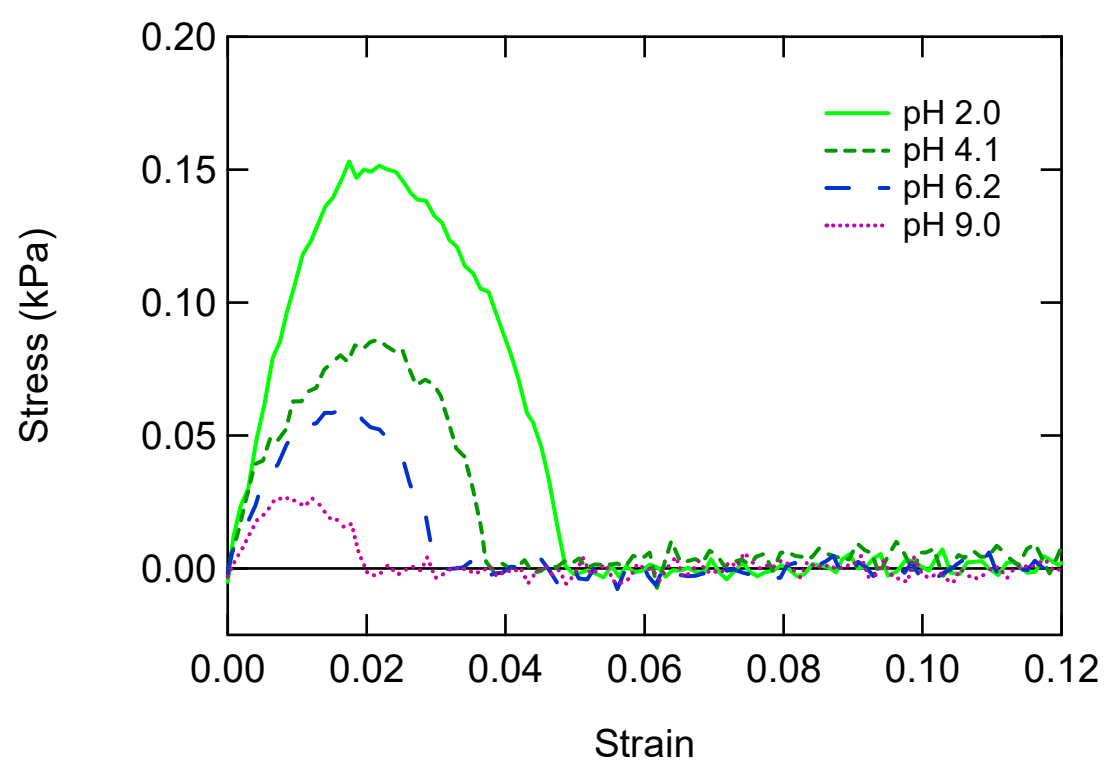




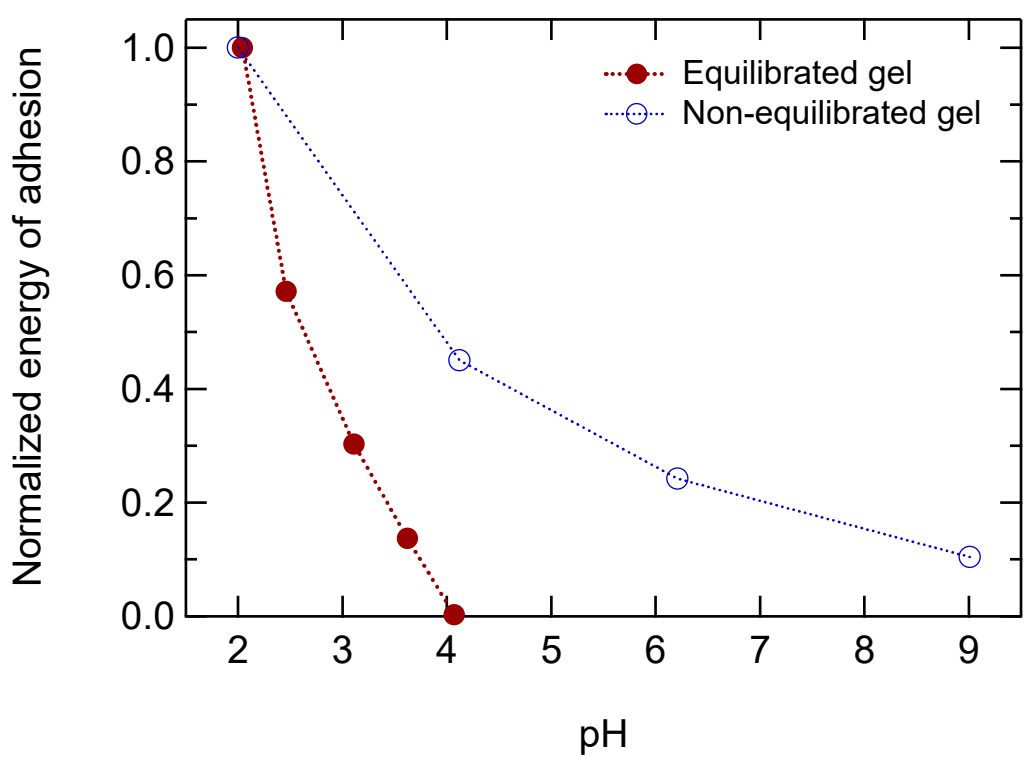

Figure 7 - Stress-strain curves (top) at different pH for PDMA gels when changing the $\mathrm{pH}$ in situ, starting from $\mathrm{pH}$ 2; we wait $5 \mathrm{~min}$ between equilibration of the solution and the beginning of the adhesion test (top). Corresponding normalized energy of adhesion (bottom) as a function of $\mathrm{pH}$, for equilibrated gels (from Figure 4).

\section{REARRANGEMENT KINETICS OF THE COMPLEXES BY VARYING THE TIME OF CONTACT}

The energy of adhesion between a PDMA hydrogel and a PAA-c brush is the strongest at $\mathrm{pH}$ around 2. However, the strength of the interactions depends on the contact time. With the same materials that have been used in the $\mathrm{pH}$ dependence study, we have measured the work of adhesion while varying the time of contact. The contact stress was fixed at $4 \mathrm{kPa}$ and the debonding velocity at 10 $\mu \mathrm{m} \mathrm{s}^{-1}$.

Figure 8 (top) represents the stress-strain curves obtained when varying the contact time from $30 \mathrm{~s}$ to $3000 \mathrm{~s}$ and the measured energies of adhesion are represented in Figure 8 (bottom).

After a $10 \mathrm{~s}$ contact, no adhesion peak was visible. For contact times higher than $30 \mathrm{~s}$, a small peak of adhesion is measured and the energy of adhesion then increases monotonically with contact time without any observable plateau within the range of times of contacts investigated. Longer experiments were very sensitive to vibrations and could not be successfully carried out with our setup. 

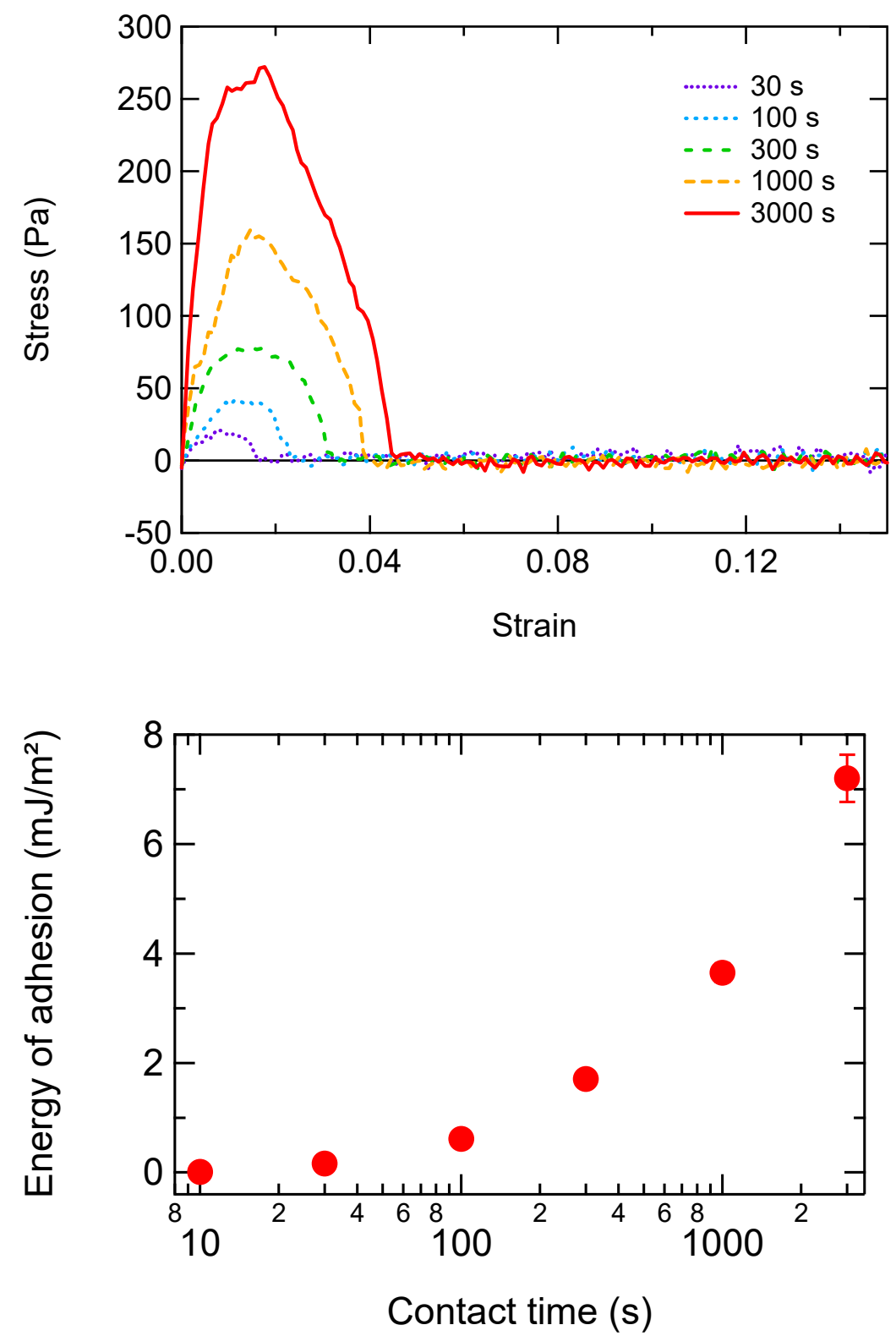

Figure 8 - Stress-strain curves (top) and energies of adhesion (bottom) between a PAA-c brush and a PDMA hydrogel equilibrated and immersed at $\mathrm{pH} 2$, as a function of contact duration. The measurement at $10 \mathrm{~s}$ did not show any adhesion peak.

\section{DEBONDING VELOCITY}

The stress-strain curves for a system identical to that described in the previous paragraph are shown in Figure 9 (top) for experiments carried out at various debonding velocities at $\mathrm{pH}$ 2. The contact is maintained during $300 \mathrm{~s}$ at $4 \mathrm{kPa}$. The energies of adhesion calculated from these curves are represented as a function of the debonding velocity in Figure 9 (bottom) along the energy of adhesion for the same experiments performed for gels equilibrated at $\mathrm{pH} 9$. 

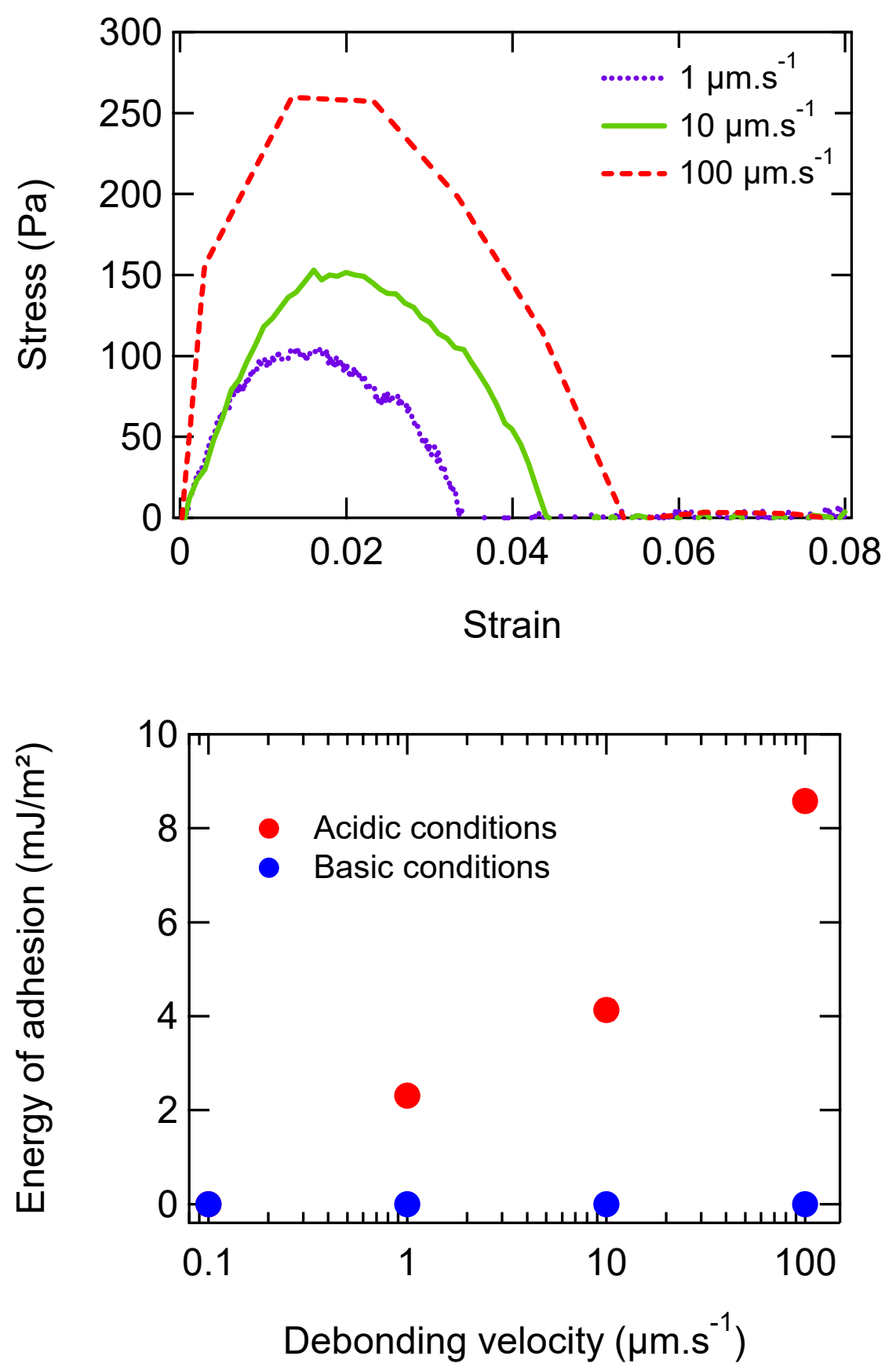

Figure 9 - Top: Stress-strain curves between a PAA-c brush and a PDMA hydrogel equilibrated and immersed at $\mathrm{pH} 2$ as a function of debonding velocity. The measurement at $0.1 \mu \mathrm{m} \mathrm{s}^{-1}$ did not show any adhesion peak. Bottom: energy of adhesion for the experiments of the top graph and for the same experiments carried out at pH9.

For a debonding velocity as low as $0.1 \mu \mathrm{m} \mathrm{s}^{-1}$, no adhesion peak was measured. Then, for increasing debonding velocities, the energy of adhesion increases almost logarithmically with debonding velocity. Interestingly, if the same experiments are carried out with gels equilibrated at $\mathrm{pH} 9$ no 
adhesion is measured regardless of velocity. This precludes hydrodynamic effects during debonding (i.e. dissipation in the fluid) which would occur in both cases. Furthermore, the fact that no adhesion is measured at low velocity suggests that the effect is mainly controlled by the time dependence of the interactions.

\section{DISCUSSION}

Several of our results are completely new and deserve to be discussed a bit further. First of all, the macroscopic energies of adhesion that we measure are very low (on the order of a few $\mathrm{mJ} \mathrm{m}^{-2}$ and up to about $100 \mathrm{~mJ} \mathrm{~m}^{-2}$ ). These values are much lower than what is typically observed for adhesion in air. This is not surprising since the effect of surface tension is suppressed. However, the implication is that $\mathrm{H}$-bonding alone in water is not sufficient to create a strong interaction. The fact that water is a competitor for $\mathrm{H}$-bonding certainly plays a big role as discussed theoretically. ${ }^{40,41}$ Then, the very strong dependence on the time of contact suggests that the reorganization of the interactions at the interface - for optimizing the number of simultaneous $\mathrm{H}$-bonds - is a slow process. This slow kinetics appears counterintuitive since both polymers are in a good solvent with a low viscosity. However, when the polymers interact, they form a phase rich in polymer, containing very little solvent, which may explain why the kinetics is slowed down. Then, to obtain a rearrangement of a part of the chain, the chains have to follow a dynamic similar to the one involved in reptation of arm stars: the chains of the brush have to break a few bonds at a time to induce a new path through the gel and increase the number of interactions. La Spina et al. ${ }^{25}$ have not shown the effect of the contact time on their results but have used a contact time on the order of $15 \mathrm{~min}(900 \mathrm{~s})$ which is similar to the contact time chosen for our usual experiments (300 s).

Once multiple $\mathrm{H}$-bonds per chain have formed, the energy necessary to break them increases dramatically with probe pulloff velocity. Although a direct comparison of the macroscopic scale and molecular scale is not very reasonable, the trends suggest that once a stronger bond is formed, it takes some time to break all bonds simultaneously. Note, however, that interactions are reversible since a long contact time followed by a very slow debonding results in no measurable adhesion, in other words the $\mathrm{H}$-bonds are indeed dynamic.

It is interesting to quantitatively compare the measured energy of adhesion with the molecular bond energy: 


$$
W_{\mathrm{adh}}(k T \text { per chain })=\frac{W_{\mathrm{adh}}\left(\mathrm{mJ} \mathrm{m}^{-2}\right)}{4.1 \times \sigma\left(\text { chain n }^{-2}\right)}
$$

Using equation (4) and the values obtained at pH 2 in Figure 6, the energy of adhesion for the PDMA gel on the brush is estimated at $51 k T$ per chain, lower than what is found for PAM gel, that is to say $280 k T$ per chain. Even if the interaction between the brush and the gel, and particularly the PDMA gel, cannot only correspond to breakup of $\mathrm{H}$-bonding, these energies can be compared in terms of number of $\mathrm{H}$-bonds per chain. In the case of the PDMA hydrogel, the energy of adhesion would correspond to a few $\mathrm{H}$-bonds per chains $\left(\sim 10 \mathrm{kT}\right.$ per $\mathrm{H}$-bonds $\left.{ }^{42}\right)$. For the PAM hydrogel, the dissipated energy per chain is too high to be attributed to a sum of $\mathrm{H}$-bonds consistent with a picture of multiple $\mathrm{H}$-bonding per chain.

An important result is the discrepancy between the behavior in dilute solution (where PAM forms complexes at a lower $\mathrm{pH}$ with PAA than PDMA) and the gel-brush interface where PAM forms adhesive interactions at a much higher pH than PDMA. This discrepancy strongly suggests that kinetic effects play an important role. If, at the interface, the PAM-PAA polymeric pair tends to rearrange its complexes more slowly and the complexes are more stable than the PDMA-PAA pair, the energy of adhesion will be stronger. It is also possible that, for steric reasons, the formation of an $\mathrm{H}$-bond in PAM favors the formation of a neighboring one, giving rise to cooperative effects favoring multiple $\mathrm{H}$ bonding. Such multiple $\mathrm{H}$-bonds, if they occur, would clearly strengthen adhesive interactions. ${ }^{43,44}$ Molecular simulations incorporating $\mathrm{H}$-bonds and polymer chain conformation taking into account correctly entropic effects could be, in principle, used to attempt a more accurate interpretation of our data. 29,45

Finally, it is worthwhile to discuss the potential effect of entanglements between the brush and the gel. In adhesion between elastomeric networks and tethered brushes, it has been shown that the entanglements between the brush and the elastomers were responsible for an increase in adhesion energy which could be quite significant even at vanishing crack velocity. ${ }^{46}$ However, the main argument for this increase at vanishing crack velocity was the exposure of the chains to air. ${ }^{47}$ Because of the low interfacial tension between the polymer and water, extraction of entangled chains from the gel does not contribute to the work of adhesion and one does not expect any contribution of entanglements. Yet the availability of sites for $\mathrm{H}$-bonding on both sides of the interface (brush and gel) must play a major role in the buildup of adhesion with contact time and in the final strength of the bond. 
Our results show that on both counts the times involved are rather long, on the order of minutes at least.

\section{CONCLUSION}

The first objective of this work was to develop a new simple, yet reliable, experimental setup designed to measure the macroscopic adhesion of hydrogels on surfaces in order to be close to the phenomena that can be met in the marine environment or in the muco-adhesion. We succeeded in obtaining quantitative values of the macroscopic energies of adhesion under immersed conditions in a reproducible way.

The materials that can be probed are often easily synthesized since they are flat sheets. The samples we put in contact consist of:

- a planar brush grafted on a $1 \mathrm{~cm}^{2}$ silicon wafer, the latter being stuck on a punch;

- a $1 \mathrm{~mm}$ thick gel covalently attached on a quartz slide.

The sizes of the samples were adapted for a reasonable degree of confinement of the gel layer $(a / h=$ 5) so that the alignment between the two surfaces remained easy. Furthermore, the contact area was large enough to perform quantitative measurement of forces with standard load cells. The environmental conditions (temperature, nature of the solvent) can be changed in situ. The space inside the sample trough allows the measurement of the characteristics of the solution by inserting measurement electrodes for temperature, $\mathrm{pH}$ or ionic strength or to change its properties, for instance by imposing a potential with a working electrode.

The possibility to tune the adhesive properties of a gel by using a polymer brush sensitive towards its environment has been demonstrated. By using a PAA brush, the energy of adhesion was nil at high $\mathrm{pH}$ and up to $10 \mathrm{~mJ} \mathrm{~m}^{-2}$ for PDMA hydrogels while it reached $100 \mathrm{~mJ} \mathrm{~m}^{-2}$ with PAM hydrogels at low $\mathrm{pH}$. Both results are fully reversible if the gel is conditioned back to a high $\mathrm{pH}$. Qualitatively, the variation of the adhesion with the $\mathrm{pH}$ occurred as expected: adhesion was weaker with increasing $\mathrm{pH}$ and vanished above a critical value close to the range of $\mathrm{pH}$ for which the interpolymer complexes cannot form in solution.

We demonstrated that the time of contact and the debonding velocity are key parameters controlling the measured energies of adhesion. Varying systematically equilibration time, contact time and debonding velocity gave access to the kinetics (i) of formation of the complexes at the 
interface, (ii) to their half-lives and (iii) to the diffusion properties of the $\mathrm{pH}$ inside the gels. We show that the establishment of equilibrated $\mathrm{H}$-bonded complexes is particularly long since the energy of adhesion continues to increase as a function of contact time in the range of an hour. We also show that the diffusion of the $\mathrm{pH}$ inside the gel is a slow process since with a short equilibration time for the gel, adhesion energies were found positive at $\mathrm{pH}$ for which no complexes ought to have been formed.

We found a significantly larger adhesion level between PAM gels and PAA brushes than between PDMA and PAA, a result which remains unexplained but may be due to cooperative effects where the formation of an $\mathrm{H}$-bond favors the formation of a neighboring one.

\section{ACKNOWLEDGEMENTS}

We thank the ANR sponsored project ADHGEL for its financial support.

7. REFERENCES

(1) Leger, L.; Creton, C. Philos T R Soc A 2008, 366, 1425.

(2) Creton, C. Mrs Bull 2003, 28, 434.

(3) Shull, K. R. Mater. Sci. Eng. R-Rep. 2002, 36, 1.

(4) Eisenriegler, E.; Kremer, K.; Binder, K. J Chem Phys 1982, 77, 6296.

(5) Dobrynin, A. V.; Rubinstein, M. Prog Polym Sci 2005, 30, 1049.

(6) Netz, R. R.; Andelman, D. Phys Rep 2003, 380, 1.

(7) De Gennes, P. G. J Phys-Paris 1976, 37, 1445.

(8) Alexander, S. J Phys-Paris 1977, 38, 977.

(9) Alexander, S. J Phys-Paris 1977, 38, 983.

(10) Skvortsov, A. M.; Gorbunov, A. A. Vysokomolekulyarnye Soedineniya Seriya A 1986, $28,73$.

(11) Shull, K. R. J Chem Phys 1991, 94, 5723.

(12) Chan, D. Y. C.; Horn, R. G. J Chem Phys 1985, 83, 5311. 
(13) Neuman, K. C.; Nagy, A. Nat Methods 2008, 5, 491.

(14) Ducker, W. A.; Senden, T. J.; Pashley, R. M. Nature 1991, 353, 239.

(15) Butt, H. J.; Jaschke, M.; Ducker, W. Bioelectroch Bioener 1995, 38, 191.

(16) Luckham, P. F. Adv Colloid Interfac 2004, 111, 29.

(17) Israelachvili, J. N.; Adams, G. E. Nature 1976, 262, 773.

(18) Israelachvili, J. N.; Adams, G. E. J Chem Soc Farad T 1 1978, 74, 975.

(19) Johnson, K. L.; Kendall, K.; Roberts, A. D. Proc R Soc Lon Ser-A 1971, 324, 301.

(20) Chaudhury, M. K.; Whitesides, G. M. Langmuir 1991, 7, 1013.

(21) Haidara, H.; Chaudhury, M. K.; Owen, M. J. J Phys Chem-Us 1995, 99, 8681.

(22) Nolte, A. J.; Chung, J. Y.; Walker, M. L.; Stafford, C. M. Acs Appl Mater Inter 2009, 1, 373.

(23) Loskofsky, C.; Song, F.; Newby, B. M. Z. J Adhesion 2006, 82, 713.

(24) Sakasegawa, D.; Suzuki, A. J Polym Sci Pol Phys 2009, 47, 1778.

(25) La Spina, R.; Tomlinson, M. R.; Ruiz-Perez, L.; Chiche, A.; Langridge, S.; Geoghegan, M. Angew Chem Int Edit 2007, 46, 6460.

(26) Flory, A. L.; Brass, D. A.; Shull, K. R. J Polym Sci Pol Phys 2007, 45, 3361.

(27) Guvendiren, M.; Brass, D. A.; Messersmith, P. B.; Shull, K. R. J Adhesion 2009, 85, 631.

(28) Kamino, K. J Adhesion 2010, 86, 96.

(29) Tagliazucchi, M.; de la Cruz, M. O.; Szleifer, I. P Natl Acad Sci USA 2010, 107, 5300.

(30) Orakdogen, N.; Okay, O. J Appl Polym Sci 2007, 103, 3228.

(31) Gundogan, N.; Okay, O.; Oppermann, W. Macromol Chem Physic 2004, 205, 814.

(32) Sudre, G.; Siband, E.; Hourdet, D.; Creton, C.; Cousin, F.; Tran, Y. Macromol Chem Physic 2012, 213, 293.

(33) Webber, R. E.; Shull, K. R.; Roos, A.; Creton, C. Phys Rev E 2003, 68.

(34) Takigawa, T.; Morino, Y.; Urayama, K.; Masuda, T. Polym Gels Netw 1996, 4, 1.

(35) Lin, W. C.; Shull, K. R.; Hui, C. Y.; Lin, Y. Y. J Chem Phys 2007, 127.

(36) Haraguchi, K.; Li, H. J.; Okumura, N. Macromolecules 2007, 40, 2299.

(37) Monteux, C.; Tay, A.; Narita, T.; De Wilde, Y.; Lequeux, F. Soft Matter 2009, 5, 3713.

(38) Muller, P.; Sudre, G.; Theodoly, O. Langmuir 2008, 24, 9541. 
(39) Sudre, G.; Tran, Y.; Creton, C.; Hourdet, D. Polymer 2012, 53, 379.

(40) Dormidontova, E. E. Macromolecules 2002, 35, 987.

(41) Ren, C.-I.; Nap, R. J.; Szleifer, I. The Journal of Physical Chemistry B 2008, 112, 16238.

(42) Douglas, B. D.; McDaniel, D. H.; Alexander, J. J. Concepts and Models of Inorganic Chemistry; 3rd Edition ed.; John Wiley \& Sons: New York, 1994.

(43) Roman, M.; Cannizzo, C.; Pinault, T.; Isare, B.; Andrioletti, B.; van der Schoot, P.; Bouteiller, L. J Am Chem Soc 2010, 132, 16818.

(44) Świergiel, J.; Jadżyn, J.; Bouteiller, L. The Journal of Physical Chemistry B 2009, 114, 737.

(45) Tagliazucchi, M.; Calvo, E. J.; Szleifer, I. Aiche J 2010, 56, 1952.

(46) Creton, C.; Brown, H. R.; Shull, K. R. Macromolecules 1994, 27, 3174.

(47) Leger, L.; Raphael, E.; Hervet, H. Adv Polym Sci 1999, 138, 185. 